\title{
OS FIOS DA MEMÓRIA: FÁBRICA RHEINGANIZ ENTRE PASSADO, PRESENTE E PATRIMÔNIO
}

\author{
Maria Leticia Mazzucchi Ferreira \\ Universidade Federal de Pelotas - Brasil
}

Resumo: Este artigo pretende discutir as dimensões que assumem as noções de trabalho, memória e patrimônio nas narrativas de antigos trabalhadores da Fábrica Rheingantz, localizada em Rio Grande (RS). Essa fábrica, fundada no final do século $X I X$, foi uma das bases sobre a qual se articulou a economia e urbanização dessa cidade, constituindo-se em referência e marco simbólico da Rio Grande moderna. Os remanescentes do complexo fabril figuram hoje como restos de passado num presente tensionado entre as reivindicações patrimoniais e a lógica do mercado imobiliário numa cidade que vivencia um novo ciclo de crescimento econômico.

Palavras-chave: Fábrica Rheingantz, memória, patrimônio, trabalho.

\begin{abstract}
This article intends to discuss the dimensions that work impressions, memory and heritage can assume through the narratives of the former workers of the Rheingantz Factory, sited in Rio Grande, RS. This plant, founded in the late 19th century, was a foundation for the economy and the urbanization of the this city, as well as a reference and simbolic landmark of the modern Rio Grande. Today, the remainders of that plant are the remains of a past whithin a present tensioned between heritage reivindications and the logic behind the real estate market, in a city that experiences a new cicle of economic growth.
\end{abstract}

Keywords: heritage, memory, Rheingantz Factory, work.

Este artigo foi elaborado a partir de pesquisa realizada sobre a Fábrica Rheingantz, localizada na cidade de Rio Grande, sul do Brasil. Essa investigação ocorreu em dois momentos distintos: o primeiro deles entre 1998 
e $2002^{1}$ e o segundo entre os anos 2009 e 2012. Podemos considerar um terceiro momento, que inicia por ocasião do anúncio formal do tombamento do complexo Rheingantz pelo Instituto do Patrimônio Histórico do Estado (Iphae), em julho de 2012, ${ }^{2}$ cujos efeitos e ressonâncias serão objeto de investigação e análise futuras.

O período entre 1998 e 2002 foi caracterizado pelo contato mais direto e sistemático com a Fábrica Rheingantz, entendida aqui como um conjunto composto pelo prédio fabril propriamente dito e suas extensões, como o local onde funcionaram a Sociedade Mutualidade, ${ }^{3}$ o ambulatório médico, o Clube União Fabril, o Grupo Escolar Comendador Rheingantz, as chamadas "casas da fábrica” e a Vila São Paulo, na qual se localizam também as casas de operários. A pesquisa realizada teve por objetivo recuperar a trajetória da empresa a partir de relatos orais e de outras fontes, bem como fazer um registro do que ainda permanecia no local, como edificações, maquinário, mobiliário e acervo documental. ${ }^{4}$

A Fábrica Rheingantz ou União Fabril, como também é conhecida, foi uma das maiores fábricas têxteis do sul do Brasil surgidas no século XIX. A partir dela a cidade avançou em processos de urbanização com a introdução de sistemas de transporte urbano, tais como o bonde, a implantação de serviços públicos no bairro Cidade Nova, reduto da população imigrante e operária e a dinamização de setores como o ferroviário e o portuário, tendo em vista o fluxo de produção e de matérias-primas. Igualmente, a afirmação de um setor industrial composto por diferentes empreendimentos, aliado ao setor de transportes, como a Viação Férrea e o Porto, consolidou uma classe operária protagonista de vários movimentos políticos e reivindicatórios na cidade de Rio Grande.

\footnotetext{
Ver Ferreira (2002).

Ver Rio Grande do Sul (2012).

3 A Sociedade Mutualidade dos operários da Companhia União Fabril (CUF) foi fundada em 10 de março de 1881 e tinha, dentre suas atribuições, gerir fundos de auxílio aos trabalhadores. A partir dos anos 1950, passou a funcionar também como cooperativa, na qual os funcionários da empresa podiam adquirir produtos como botijões de gás, tecidos, calçados, etc. Todas as compras eram repassadas ao setor de departamento pessoal da empresa para que fosse feito o devido desconto na folha de pagamento do trabalhador.

4 No período em que estive pesquisando a fábrica, tive acesso a diversos fundos documentais, tais como as fichas do departamento pessoal que remontavam a 1937, prontuários do ambulatório médico da empresa, documentos gerais relativos ao fluxo de produção, documentos técnicos, atas das reuniões da diretoria da Fábrica Rheingantz, cartas do comendador Carlos Guilherme Rheingantz quando no exercício da direção, dentre outros. Ressalte-se que já naquele momento uma grande parte dessa documentação estava armazenada em ambientes totalmente insalubres, estando sujeita a ataques biológicos, umidade, contato com materiais corrosivos e outros fatores de degradação.
}

Horizontes Antropológicos, Porto Alegre, ano 19, n. 39, p. 69-98, jan./jun. 2013 
O segundo momento de pesquisa tem como referência a audiência pública realizada na Câmara de Vereadores da cidade de Rio Grande em 9 de julho de 2009. Tendo sido convidada a participar dessa audiência, como pesquisadora da Rheingantz, pude observar alguns movimentos que me pareceram, naquele momento, a demonstração de uma expressão de resistência diante do desaparecimento dos traços memoriais e do direito ao que consideram uma dívida da empresa: a regularização da posse das casas que pertencem à massa falida União Fabril. A audiência pública foi marcada pela intervenção de representantes do poder público, legislativo e judiciário, o que foi importante para acelerar o processo de patrimonialização do complexo Rheingantz, inaugurando, simbolicamente, o tempo do patrimônio em contraposição ao tempo da memória, que parece ter caracterizado o período anterior.

Entre esses dois tempos, busco analisar como operam conceitos como o de memória coletiva, trabalho e patrimônio, tendo como referência relatos orais e fontes documentais, traçando aquilo que denominei como uma etnografia da perda.

A metodologia utilizada na primeira fase da pesquisa baseou-se principalmente na observação de encontros promovidos por antigos trabalhadores da empresa e as formas de ocupação do espaço da fábrica; no registro de histórias de vida de pessoas que compuseram o quadro funcional da Rheingantz no período 1950-1970, ${ }^{5}$ na pesquisa em acervos documentais da empresa, em arquivos públicos e em acervos que se encontram em posse dos ex-funcionários.

Esse universo de análise composto pelos ex-trabalhadores foi se revelando como extremamente complexo, pois a forma nostálgica como se referiam ao passado, "os bons tempos da Rheingantz", ao mesmo tempo em que ocultava as fissuras sociais, homogeneizando e contemporizando os conflitos, revelava estratégias e dispositivos engendrados para afirmar identidades num contexto - o do presente - no qual as circunstâncias de vida no plano pessoal e o cenário econômico apontavam para quadros de penúria, desemprego e perda da crença numa recuperação do potencial fabril da cidade. Entre 1997 e 1998, período em que comecei a pesquisa, outro problema se colocava no plano local: as casas ocupadas por grande parte dos entrevistados, as quais

\footnotetext{
5 O período entre 1950 e 1970 foi tomado levando-se em consideração que no começo dos anos 1950 a fábrica ainda apresentava índices de crescimento, os quais iniciam um processo de declínio a partir do final dessa década, culminando com seu fechamento em 1968.
} 
pertenciam originalmente à Fábrica Rheingantz, estavam sendo requisitadas pela direção da Inca Têxtil, nome que assumiu a fábrica depois de ter sido vendida em 1970. Num processo extremamente conturbado, a Inca Têxtil propunha aos moradores das casas que as adquirissem no valor de mercado, o que gerou protestos fundamentados, de acordo com os moradores, no princípio da justiça: as casas, segundo eles, deveriam fazer parte de um ajuste de contas que nunca foi feito entre a empresa e aqueles que em 1968 ficaram sem salário por seis meses e, posteriormente, sem emprego.

O processo de declínio e obsolescência que marcou a trajetória dessa fábrica pode ser compreendido num contexto de crise geral de um modelo empresarial familiar, que, sobretudo na área têxtil, trouxe profundas desarticulações na organização e relação dos sujeitos com o trabalho.

As narrativas desses sujeitos, cujas trajetórias estiveram entrecruzadas pelo trabalho na fábrica, apontam para uma identidade associada ao espaço fabril, o qual, destituído de suas características como um lugar de trabalho e sofrimento, opera no presente como um lugar de memória no sentido atribuído por Pierre Nora (1984): uma condensação e cristalização de memória levando em consideração congregar as dimensões material, simbólica e funcional.

Tensionadas entre aquilo que se deve ou não recordar e o que se deve ou não esquecer, a memória e a narrativa do trabalho são produzidas no contexto das condições sociais, individuais e coletivas, contexto no qual as interpretações, as reapropriações e os usos do passado permitem reconstruí-lo da forma como melhor responde às incertezas do presente (Luca, 2011).

\section{Uma fábrica oitocentista: a Rheingantz dos "bons tempos"}

A Fábrica Rheingantz foi oficialmente inaugurada pelo empreendedor de origem renana Carlos Guilherme Rheingantz em sociedade com o sogro, Miguel Tito de Sá, e com o empresário alemão Hermann Vater, no prédio que ocupa, na Avenida Rheingantz $\mathrm{n}^{\circ} 210$, no ano de 1873, sob o nome de Fábrica Nacional de Tecidos e Panos de Rheingantz \& Vater, em forma de sociedade comanditária. ${ }^{6}$ A fábrica entrou em operação efetiva no ano seguinte

6 Conforme dados apresentados no Relatório da Associação Comercial publicado no jornal Diario de Rio Grande (1887). 
e trabalhou prioritariamente com o processamento da lã, cuja procedência era das propriedades rurais nas regiões de Bagé, Livramento, Uruguaiana e Santa Vitória do Palmar, no sul do Rio Grande do Sul.

Impondo-se como pioneira no setor têxtil no sul do Brasil, a Rheingantz ocupou o lugar de uma grande empresa nos finais do século XIX, configurando-se num nível produtivo que abarcava um mercado consumidor de grandes proporções, extrapolando as fronteiras regionais (Hardman; Leonardi, 1982, p. 173). As primeiras mudanças na organização da empresa ocorreram em 1891, quando a sociedade que dera origem à Rheingantz \& Vater foi desfeita, transformando-se em Sociedade Anônima União Fabril e elegendo sua primeira diretoria, composta por Carlos Guilherme Rheingantz com o controle acionário.

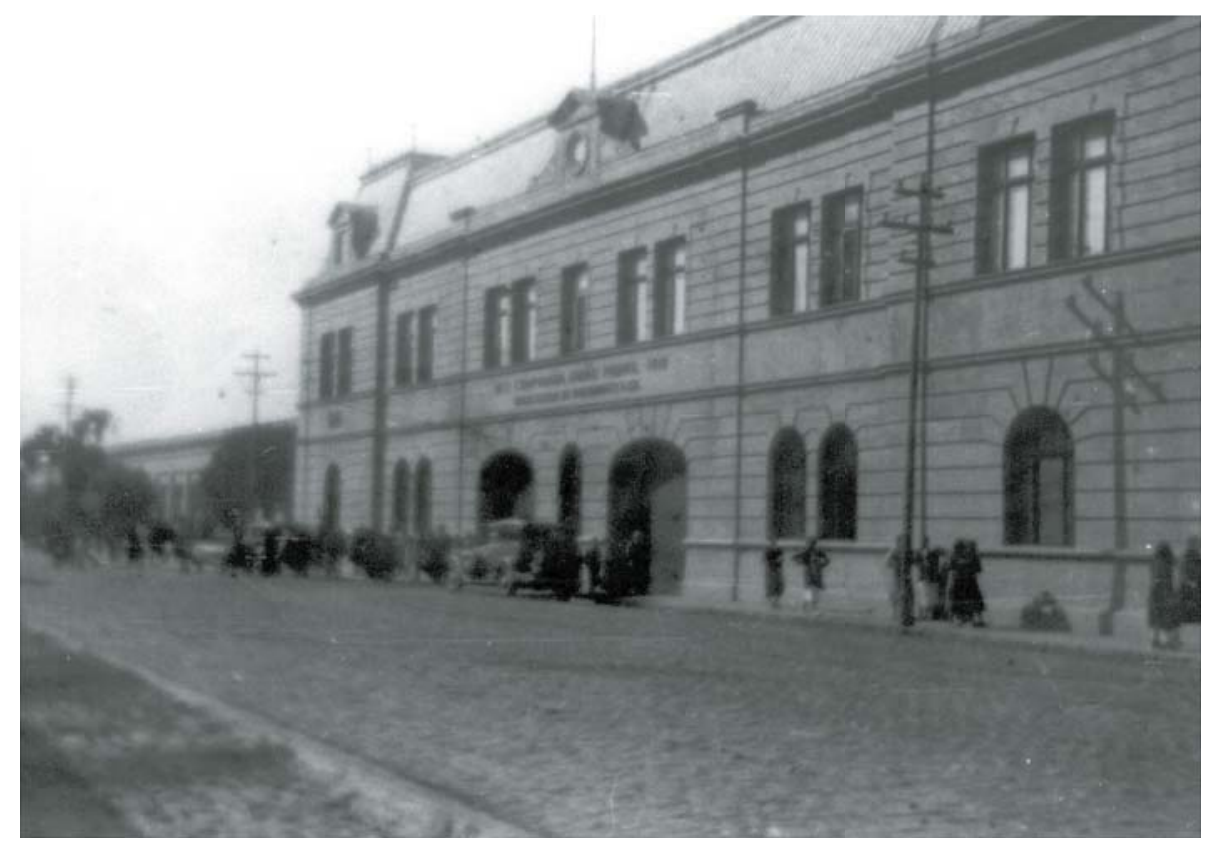

Figura 1. Fábrica Rheingantz, década de 1950 (acervo Fototeca Municipal de Rio Grande). 
O projeto fabril do fundador é apresentado nos relatos de seus descendentes como resultante de sua experiência na Alemanha e em viagens que realizou à Inglaterra para conhecer fábricas têxteis. No Rio Grande do Sul, terra onde vivia seu grupo familiar, buscou encontrar um local propício à instalação de uma indústria nos moldes das que havia conhecido na Europa. E a cidade de Rio Grande foi assim escolhida principalmente por já possuir um porto capaz de receber embarcações comerciais, o que facilitava a importação de equipamentos necessários à produção têxtil.7 Durante as primeiras três décadas do século XX, a empresa ampliou e aprimorou o processo de fabrico de tecidos de lã e para tanto incentivou a vinda de estrangeiros, predominando os alemães nos setores técnicos da empresa. Em outros setores, como carpintaria, marcenaria e tapeçaria, os mestres eram igualmente de origem europeia, tais como italianos, poloneses e portugueses.

Não contrariando o modelo oitocentista de indústria, no qual o fundador centraliza consigo a direção do empreendimento, bem como estabelece uma relação muito estreita com a política local, veem-se exemplos dessa relação na presença de Carlos Guilherme Rheingantz na comissão provisória instaurada para a administração do município por ocasião da proclamação da República, em 1889. Entretanto, foi no campo das iniciativas sociais que a Fábrica Rheingantz mais se destacou, criando dispositivos de implantação e regulamentação de benefícios, como a Sociedade Mutualidade, mantida por contribuições dos empregados da empresa e atuando no atendimento médico, na concessão do auxílio pecuniário aos sócios temporariamente impedidos de trabalhar e no auxílio-funeral. O surgimento do "Fundo de Auxílios Carlos G. Rheingantz" foi responsável pela implantação de benefícios, como aqueles concedidos em razão da viuvez feminina, do amparo concedido aos filhos menores, da invalidez resultante de algum acidente na fábrica e do casamento de operárias, este desde que formalmente consentido pelos pais. A organização de uma biblioteca e de aulas direcionadas aos empregados são reflexos desse perfil do fundador, representado nas narrativas dos trabalhadores e nos textos produzidos sobre a fábrica como um erudito. A biblioteca foi organizada no

\footnotetext{
O período que vai de 1870 a 1920 caracterizou-se pelo desenvolvimento de setores fundamentais que impulsionaram a cidade de Rio Grande. Durante o século XIX, a cidade exerceu papel fundamental no contexto regional, principalmente no que se refere a configurar-se como entreposto comercial sul-rio-grandense.
}

Horizontes Antropológicos, Porto Alegre, ano 19, n. 39, p. 69-98, jan./jun. 2013 
prédio que abrigava o Cassino dos Mestres e estava entre os fins aos quais se destinava a Sociedade de Mutualidade. Manter uma biblioteca cumpriria a função de “desenvolver a cultura dos sócios”, conforme artigo do Estatuto da Sociedade de Mutualidade. ${ }^{8}$

A representação do fundador como um homem culto, justo, oscilando entre uma figura paternal e um patrão punitivo, é recorrente nas memórias vinculadas a lugares de trabalho, demonstrando como as lembranças constituem-se numa distensão de tempo, na qual o passado, momento em que afloravam os sentimentos de animosidade e revolta, é retrabalhado pelo presente, já liberado dessas contraturas (Lasmènes, 2011).

Entre os anos 1920 e 1940, a indústria têxtil como um todo sofreu os reveses de crises internacionais, ainda que, em alguns setores e pontualmente, tenha sido beneficiada por uma situação de guerra. Dos finais da década de 1940 até meados dos anos 1950 foi possível manter um nível de produção que possibilitava à empresa funcionar em todos os setores, garantindo ao menos uma relativa estabilidade que escondia, de fato, os processos conturbados nos quais se desenvolvia a administração do último representante da família Rheingantz. O período entre 1960 e 1970 foi marcado por várias crises, que acarretaram no término de um ciclo na história da empresa, cujo ápice foi a decretação da falência da mesma em 1968, sendo reaberta em 1970 com outro nome social, Companhia Inca Têxtil, e outro corpo administrativo, sem o controle acionário da família Rheingantz. Os processos indenizatórios impetrados contra a empresa, ainda no período anterior ao fechamento, nunca foram resolvidos em sua totalidade e as estratégias utilizadas para ressarcir os funcionários, tais como converter a dívida em debêntures e conferir a eles parte do lucro, rapidamente mostraram-se ineficazes, pois não contiveram o descontentamento nem impediram o crescente número de causas trabalhistas que incidiam sobre a empresa. Além disso, o endividamento da Rheingantz com a Previdência Social resultou na penhora de grande parte de seus bens, impedindo que eles fossem vendidos para amortização das dívidas trabalhistas.

Mergulhada em dívidas e sentenças judiciais, a Inca Têxtil manteve-se funcionando parcialmente até o final da década de 1980. A partir dos anos 1990,

\footnotetext{
8 A constituição da biblioteca fazia parte de um projeto maior no qual classes noturnas eram ministradas aos trabalhadores, “uma educação do espírito” como definiu o médico Augusto Duprat, que atuava como colaborador na fábrica, em sua argumentação frente à diretoria da empresa.
} 
em face do agravamento das condições financeiras e à impossibilidade de investir na manutenção básica dos prédios, a Inca Têxtil foi sendo abandonada, o que se torna visível tanto pela situação de comprometimento estrutural do edifício, como pelo desânimo e fim das expectativas de retorno aos velhos tempos.

\section{Do trabalho à memória: as metamorfoses do espaço}

No primeiro momento da pesquisa, entre os anos 1997 e 1998, o ingresso no universo da Rheingantz ocorreu através de um grupo de antigos trabalhadores que frequentavam o espaço da fábrica em alguns dias da semana. Esse grupo dividia-se em dois: um composto por mulheres e outro, por homens. O grupo feminino reunia-se uma vez por semana na sala da costuraria, e a costura era, na verdade, um mote para o encontro semanal no qual falavam de suas vidas, trocavam receitas de tricô e culinária e, invariavelmente, conversavam sobre o passado. Já os homens ficavam na antiga portaria, configurando um grupo numericamente irregular. À frente de todos, cumprindo a função de vigilante da fábrica, estava seu Hilso, autodefinido como "o guarda da Rheingantz”. Era ele quem cotidianamente abria o prédio às 7h30min, fechava às $11 \mathrm{~h} 30 \mathrm{~min}$, reabria às $13 \mathrm{~h} 30 \mathrm{~min}$ e tornava a fechar às $17 \mathrm{~h} 30 \mathrm{~min}$. Abrindo e fechando uma fábrica vazia, já completamente deteriorada pelo tempo, percorrendo pavilhões silenciosos que em nada lembravam os ruídos dos teares e filatórios, esse homem mantinha ainda um vínculo com a administração da fábrica, localizada na cidade de Pelotas, em função do qual recebia uma pequena remuneração. Seu Hilso, forma pela qual era comumente tratado, definia seu papel como o de um guardião, o representante do tempo da fábrica, o tempo da memória, que para ele era o da negação do presente. Ao falar sobre o que o motivava a permanecer numa fábrica já desativada e sem um futuro possível, dizia seu Hilso:

Eu morava lá fora, no Povo Novo. Vim para cá para trabalhar na estrada [Rede Ferroviária], mas como a estrada atrasava os pagamentos, vim para Rheingantz, aqui era melhor, pagava em dia e eu vim para cá, passou bastante tempo, e estou até hoje aqui. Peguei amor por essa casa aqui e passo dia e noite nessa fábrica. Cuido todo esse patrimônio, sábado, domingo, qualquer barulho [...] O Dr. Paulo [Diretor da Inca Têxtil] uma vez me perguntou porque eu estava aqui se quase nem pagamento eu tinha. Eu disse que é porque eu gosto daqui, vivi uma vida

Horizontes Antropológicos, Porto Alegre, ano 19, n. 39, p. 69-98, jan./jun. 2013 
aqui dentro, eu e muitos viveram uma vida aqui, tem muitos que qualquer coisa estão aqui dentro. (Hilso Gonçalves Magalhães, entrevista em 05/06/1998).

Ocupar os lugares que no passado abrigavam as atividades do trabalho parecia revelar uma reivindicação de pertencimento ao território local, espécie de apropriação simbólica do passado que ali se depositava. Essa relação entre um universo identificado pela mesma trajetória profissional e a memória que compartilham remete à noção de memória coletiva de Maurice Halbwachs (1994), no sentido de compreendê-la como representações e imagens do passado operando sobre o presente. Para Halbwachs, o espaço faz parte daquilo que ele traduziu como sendo os quadros sociais da memória, ou seja, suas condições sociais de produção. As transformações desse espaço desestabilizam a memória que ali se projeta, fazendo com que os sujeitos abstraiam-se da realidade contemporânea, significada pela ausência e esvaziamento, e recuperem do passado imagens de uma fábrica idealizada, na qual os conflitos e as divergências ficam secundarizados.

As primeiras reflexões emitidas pelos ex-trabalhadores entrevistados, fossem aqueles pertencentes ao grupo que ainda frequentava a fábrica ou aqueles que não mais mantinham contato com ela, circunscreviam-se em pares de oposição entre passado e presente, nos quais o passado expressava qualidades e valores que no presente eram negados. Expressões como: "antes a gente trabalhava o tempo todo, ia trabalhar doente, do jeito que fosse [...] hoje, essa juventude é toda fraca, qualquer gripe já entram com atestado, faltam o serviço, ninguém quer mais nada com nada” e "se vivia como numa família, a gente se entendia ali dentro e tinha respeito pelos mestres... hoje não se respeita mais nada, é cada um por si, ninguém tem mais amor ao trabalho” são algumas dessas oposições que se manifestam nas evocações do passado, quando são forjadas imagens nostálgicas do trabalho fabril em informações que muitas vezes se apresentaram contraditadas pela documentação oficial da empresa, tal como as fichas da vida funcional dos trabalhadores arquivadas no departamento pessoal.

Contando com $155.000 \mathrm{~m}^{2}$ de superfície e $45.000 \mathrm{~m}^{2}$ de área coberta, o espaço fabril estendia-se do interior da fábrica, nos locais destinados ao trabalho propriamente dito, ao exterior, em prolongamentos diretos da própria empresa, como a Sociedade Mutualidade, o ambulatório médico, o Grupo Escolar e a creche, assim como no conjunto formado por todos esses prédios e pelas casas dos mestres, contramestres e trabalhadores da fábrica. 


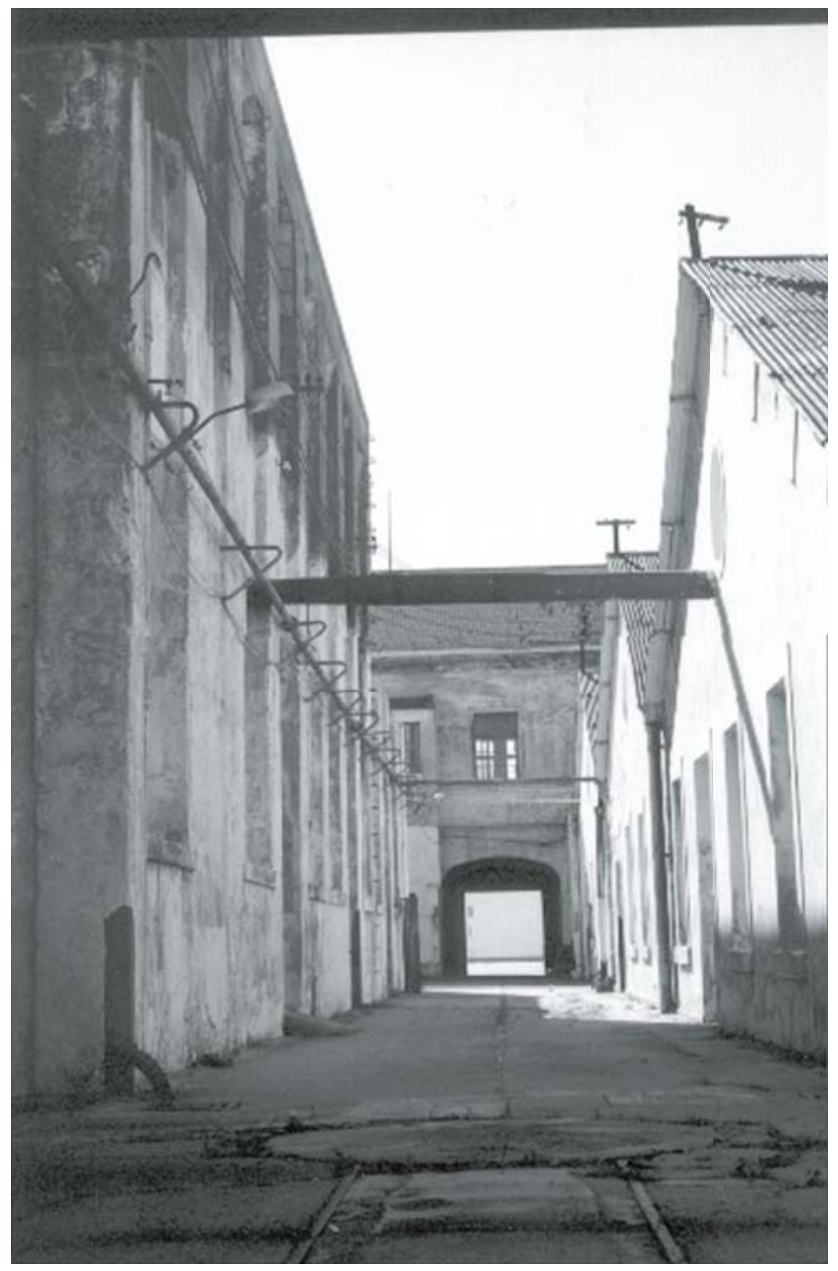

Figura 2. Corredor de entrada (acervo pessoal).

No plano interno, a referência a alguns espaços eram recorrentes nas narrativas, como, por exemplo, a portaria, local de ingresso na fábrica e onde ficavam as placas de identificação de cada operário, as quais eram entregues no momento da entrada e devolvidas no final do expediente; por vezes o tempo era escasso e, sobretudo para as mulheres que tinham filhos, via de regra 
era preciso contar com a conivência do porteiro para minimizar o atraso no serviço; o pátio interno, no qual a direção da empresa fazia-se presente em comunicados e congraçamentos, sendo referência no período dos seis meses que seguiram à suspensão do trabalho e fechamento definitivo da fábrica, era sempre mencionado, pois ali ocorriam as reuniões entre todo o grupo de funcionários, tendo sido construído um pequeno santuário à frente do qual eram dispostas velas e realizadas missas em prol de uma recuperação da empresa. No andar superior do prédio de entrada da fábrica estavam concentrados os setores financeiro e administrativo, sendo a gerência um lugar inacessível para a maior parte dos funcionários. A sala da gerência era cuidadosamente limpa pela única funcionária que, nos últimos anos, ocupava esse andar e que periodicamente arejava a sala, limpava os móveis, lustrava o assoalho. Dessa sala e de todo o chamado setor administrativo, as aberturas proporcionavam uma visão ampla do pátio central e do corredor que levava até as seções posteriores da fábrica. Subir a escada que conduzia ao andar superior remetia, nas narrativas, a uma ordem disciplinar e hierárquica que previa o acesso a esse pavimento em casos de punições, demissões ou, mais raramente, alguma solicitação de caráter pessoal.

\section{As casas da fábrica}

No espaço externo à fábrica, o conjunto de moradias que compunham as chamadas “casas da fábrica” divide-se em dois: o primeiro deles é composto por moradias dispostas ao lado do edifício fabril; e o segundo, inaugurado na década de 1950, localiza-se nas imediações da fábrica, na chamada Vila São Paulo.

Foi do primeiro conjunto de habitações que um maior número de referências foi obtido na documentação da empresa. Nesse local, cujas primeiras edificações começaram em conjunto com a fundação da fábrica em 1873, é possível, através da disposição dos imóveis, traçar um mapa social desse universo. No lado oposto ao prédio fabril encontram-se edifícios que eram segmentos da fábrica: o prédio da Sociedade de Mutualidade; a creche, sob a direção das religiosas da Ordem de São José; o Grupo Escolar Comendador Rheingantz, o qual os filhos dos operários podiam frequentar até o $4^{\circ}$ ano do ensino fundamental. Na sequência, havia construções nas quais moravam os 
mestres da fábrica, que, pelo menos até 1950, eram de nacionalidade alemã. Essas casas apresentavam-se com dois andares, porão, sótão e jardim, seguindo o padrão construtivo de influência germânica. No lado oposto da rua vê-se ainda o que foi a casa de um dos diretores da empresa, membro da família Rheingantz: uma construção grande no meio de um jardim, garagem para carros, elemento de distinção num conjunto social no qual ter um automóvel foi, por muito tempo, exclusividade dos Rheingantz.

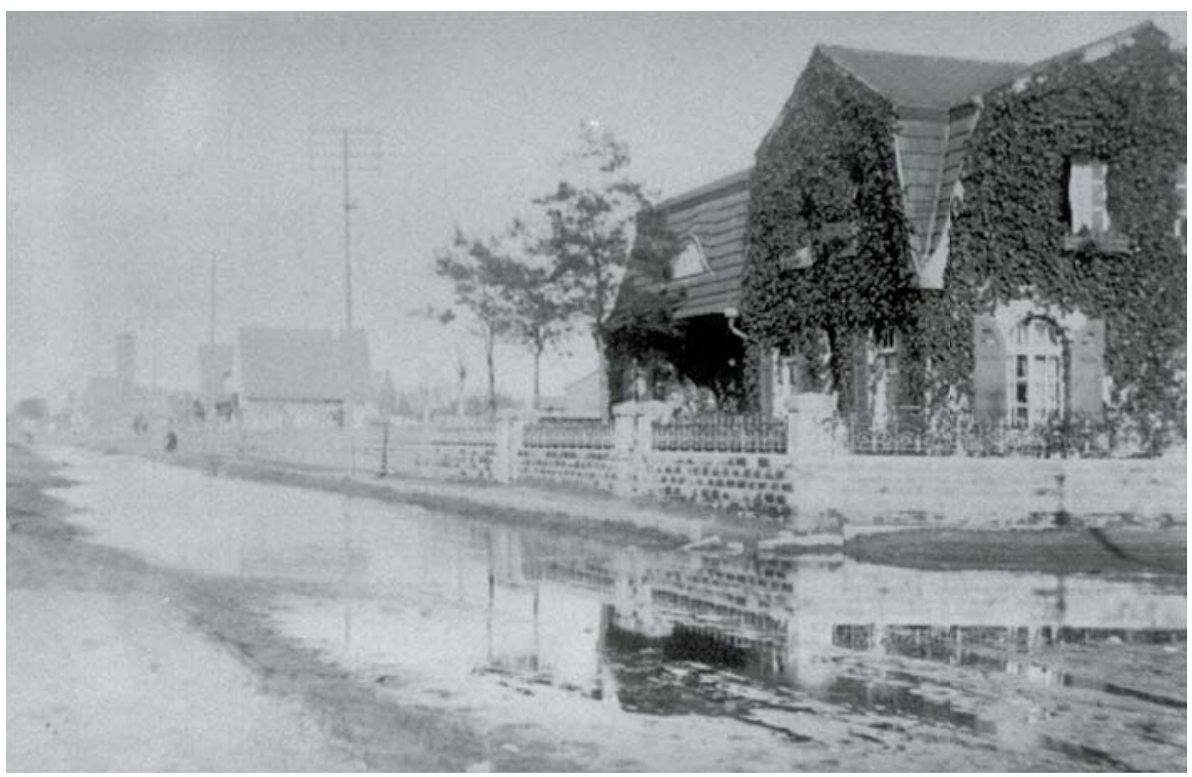

Figura 3. Casas dos mestres (acervo Fototeca Municipal de Rio Grande).

Ao lado desse grande imóvel inicia-se uma sequência de casas caracterizadas por fachada austera de porta, janela e, em algumas delas, um pequeno jardim. Imóveis que eram entregues aos contramestres. Um terceiro lote de casas está na parte interna e paralela à Avenida Rheingantz, num conjunto arquitetônico de casas em fita, ou, na linguagem local, “o corredor”. Essas eram casas originalmente cedidas a operários com família pequena ou solteiros. São residências geminadas compartilhando espaços como o pátio de distribuição interna. 
Esses espaços revelavam as estratificações e os processos de discriminação étnico-social, regidos por uma ordem baseada nas distinções e nos papéis sociais que se estabeleciam como um prolongamento do que ocorria no interior da fábrica.

Essas hierarquizações ficam evidenciadas no padrão construtivo das casas que, como signos visuais, informam sobre o sistema de relações pessoais que ali se interpunham. Sobre essas relações, algumas entrevistas foram balizadoras, como aquela obtida junto à filha de um dos mestres alemães. Pautando sua narrativa na trajetória percorrida pelo pai desde sua vinda da Alemanha até tornar-se o último dos mestres de etnia germânica a deixar a fábrica, depois de se tornar Inca Têxtil, Heldwig Ellen Bersch recompôs dados de sua infância e juventude ambientados no cenário desses arredores da fábrica. O espaço que se delineava através de sua narrativa estava marcado pela posição assumida no interior da empresa, a divisão entre o trabalho operário e o trabalho técnico, que era atributo quase exclusivo dos alemães. Assim, Heldwig dizia que "a convivência com o grupo dos técnicos, que moravam do lado direito, era diferente dos que moravam no lado esquerdo”. A disposição das moradias em lados opostos correspondia ao seccionamento que caracterizou esse conjunto social, numa interação que, no caso dos alemães, era interna aos limites do grupo, bastante fechada, tal como coloca Heldwig:

Se formou um grupo fechado... até esses dias eu falei com uma outra senhora que era filha de um empregado da Poock, e ela me disse uma coisa que, claro, a gente não sabia, “o pessoal da Rheingantz era muito cheio...” nós nos dávamos com os filhos do Hulverscheit, que eram da nossa idade... as outras eram mais velhas do que nós... mas existia uma distinção, tanto é que depois que começamos a estudar no colégio, o caminho era o mesmo e nós começamos a nos dar com a filha do mestre carpinteiro, vamos dizer assim... porque tinha carpintaria.... ele era polonês e isso não foi visto com bons olhos pela chefia, que mandou chamar meu pai. (Heldwig Ellen Bersch, entrevista em 23/09/1998).

Essas interdições baseariam-se, de acordo com Heldwig, em uma lógica interna da empresa que preconizava a harmonização dos segmentos superiores com os demais, sem que houvesse trocas mais próximas entre eles, resguardando-se assim as diferenciações, compreendidas como sendo a base dessa comunidade. 
Essas clivagens sociais eram introjetadas, no caso da comunidade de origem alemã, como uma realidade inquestionável, construída já na infância quando aos filhos dos mestres era prescrita uma socialização interna ao pequeno grupo. Sob normas comportamentais rígidas, impossibilitando a interação com os filhos dos funcionários subalternos, o que era diversão e aventura para estes, como visitar a fábrica e frequentá-la eventualmente, era vetado aos jovens descendentes de alemães, que deveriam manter uma relação muito distanciada com a fábrica e seus espaços funcionais.

A demarcação das diferenças e posições hierárquicas tinha no idioma seu principal agente. Mesmo que soubessem falar português, tal como afirma Heldwig, era indicado aos mestres que se comunicassem entre si em alemão, numa evidente estratégia de afirmação de poder sobre os demais segmentos sociais da fábrica.

A proeminência do elemento germânico fazia com que raramente outros grupos étnicos fizessem-se representar nos cargos de mais alto escalão. A partir de 1955, período em que começaram a ser implantadas medidas de modernização da empresa, a incidência de brasileiros nos cargos de comando aumentou consideravelmente. Entretanto, as narrativas evidenciam que, mais do que uma interdição às trocas culturais propriamente ditas, o que ocorria era a afirmação de estratégias de controle no meio operário.

Os casos em que, pelo compartilhamento de vizinhança, foram geradas formas de proximidade são abordados pelas narrativas como raros e excepcionais. É o que relata Sueli Botelho (1981), ex-tecelã, ao dizer:

Eu morei trinta e um anos ali na Avenida Rheingantz e morava ali o doutor Alfredo Rheingantz, que era primo do doutor João [o último descendente do fundador Carlos Guilherme Rheingantz a assumir a direção da fábrica]. Ele era casado com a Dona Dóris, e tinha três filhos... e nós brincávamos com eles, apesar de nossa família ser muito pobre, mas a mulher dele era uma santa porque não fazia distinção, eles tinham um quartinho nos fundos que era só de brinquedos, ela abria o portão do jardim e botava toda aquela criançada pobre para brincar com os filhos dela.

Essa proximidade afirmava-se como uma concessão manifesta na expressão "era uma santa”, utilizada pela informante para caracterizar a esposa do chefe. Em outros momentos, esses gestos de aproximação são traduzidos como formas de generosidade e reconhecimento. É o que aparece na fala de 
seu Hilso ao comentar sobre a doação feita a ele, por um dos mestres, de uma bicicleta que havia sido trazida da Alemanha para a filha e que havia deixado de ser utilizada com o tempo.

Dentro do universo social dos operários havia, igualmente, expressões de seccionamento e diferenciação social. O uso da expressão "gente do corredor” como elemento classificatório, referindo-se aos operários que moravam nas casas em fita, é um desses exemplos mais evidentes. Essas casas eram entregues aos operários de menor qualificação e com famílias pequenas. Entretanto, as fichas funcionais do período posterior a 1945 revelaram outra possibilidade de concessão, que se dirigia aos estrangeiros vindos da Alemanha e de outros países europeus, em geral solteiros cujo tempo de permanência na cidade não ultrapassava 12 meses.

As “casas da fábrica” estavam inscritas em contrato de obrigações operário-empresa, sendo exemplar disso o corpo de bombeiros da fábrica, composto essencialmente pelos que nelas habitavam. Além disso, cabia aos moradores zelar pela conservação dos imóveis e manterem-se dentro dos padrões comportamentais considerados aceitáveis pela empresa. Nesse sentido, o sistema de vizinhança atuava no controle de atitudes consideradas desviantes. E os relatos contidos nos documentos funcionais dos trabalhadores são evidências dessas redes formadas entre funcionários e empresa. Casos de desavenças familiares envolvendo agressões e embriaguez ou brigas entre moradores eram comunicados aos mestres pelos vizinhos e logo medidas punitivas eram acionadas, podendo ocorrer, em casos extremos, a retomada da casa pela direção da empresa. Da mesma forma, os vizinhos eram fundamentais para comprovar eventuais tentativas de burlar o serviço, tal como pode ser visto no seguinte relato: “o funcionário mandou o colega avisar que estava enfermo e quando o enfermeiro esteve em sua casa, havendo batido e ninguém tendo aparecido, foi informado pelo vizinho que o morador tinha saído”. ${ }^{9}$

A vizinhança aparece também como um lugar da ajuda mútua e de conivências que se instauravam entre os moradores. No tempo da recordação são esses valores, e não as intrigas e os conflitos, que são postos em ação para caracterizar esses espaços. O lamento pela perda da convivialidade e da solidariedade entre vizinhos é evocado no tempo da memória e relaciona-se

9 Ficha funcional n. 1024, Departamento Pessoal da Fábrica Rheingantz, 1953. 
mais às condições do sujeito no presente do que propriamente ao passado (Mathieu; Gorgeu, 2011), ou seja, a deterioração dos lugares, a ocupação das casas por locatários que não fazem parte do grupo de antigos trabalhadores da Rheingantz, a descaracterização de alguns prédios, como o da antiga creche que entre os anos 1997 e 1999 sediou uma casa noturna, a substituição do movimento de trabalhadores cruzando as ruas pelo silêncio da fábrica, a incorporação de novos atores sociais, dentre outras alterações importantes.

A questão do reconhecimento do passado compartilhado colocava-se como um elemento de diferenciação e distanciamento entre moradores recentes e antigos, aproximando estes últimos em torno da questão da regularização dos títulos de propriedade das casas.

\section{"Ali ficou minha infância"}

A fábrica aparecia representada sob diferentes construções narrativas. Para alguns era o lugar onde a infância ficou depositada, para outros era denotada como o tempo da libertação do jugo familiar. Nas narrativas, sobretudo femininas, dois momentos da vida aparecem bem delimitados: o primeiro representa a passagem da infância ao tempo do trabalho; o segundo, o término da juventude com o casamento e o nascimento dos filhos. Essa transição vinha acompanhada pela perda da sociabilidade que caracterizava as moças solteiras, e as responsabilidades domésticas ocupavam, então, todo o tempo que antes era dedicado ao lazer. No relato de Elza, uma antiga tapeceira, essa ruptura aparecia como uma demarcação forte de idades da vida:

Depois que eu casei eu nunca mais pude sair, pois todo o dinheiro que se juntava era para poder comprar uma casa para a família. Então, sempre nas segundas-feiras, eu só ficava ouvindo as outras moças contando das festas que tinham ido no final de semana, elas se emprestavam roupas e devolviam tudo na segunda-feira. Eu nunca podia ir, pois, com três filhos, eu só tinha três mudas de roupa, duas para o trabalho e uma para a igreja. (Elza Padilha, entrevista em 13/11/1999).

O casamento demarcava o começo de um tempo no qual o trabalho passava a significar a manutenção da vida familiar com progressos atestados pela aquisição de bens, como a casa própria e investimentos no conforto doméstico. 
Assim, o recurso aos serões passava a ser uma forma de aumento da renda, e a possibilidade de fazê-los aparece nos relatos como uma concessão feita por alguns mestres nas seções que funcionavam no período noturno, como a tecelagem e a fiação.

Já as referências à infância perdida, quando aparecem, não se caracterizam como uma forma de lamento, mas como condição de sobrevivência num contexto familiar que obrigava o ingresso muito cedo no mundo do trabalho. Em virtude da proibição de contratação de menores abaixo de 14 anos, algumas estratégias para burlar a lei foram postas em ação, como, por exemplo, registros de certidões falsas. Entretanto, em que pese o limite de idade, a infância mantinha-se como um comportamento residual, manifesto em atitudes de brincadeiras que eram consideradas, quando flagradas, motivo para severas punições.

Nesse universo fabril, a observação de uma sucessão familiar na composição da mão de obra aparecia nos registros oficiais da empresa, revelando que, tanto entre homens quanto entre mulheres, o ingresso na fábrica foi resultante de um encadeamento geracional através do qual os pais ou parentes próximos introduziam os filhos no trabalho. As referências à filiação nas fichas de pessoal era acompanhada pela identificação do setor no qual trabalhavam os familiares, pais ou tios. Dar sequência à trajetória aberta pelos parentes era um dado que se confirmava continuamente pela documentação; além disso, prosseguir no ofício dos pais ou parentes era, em alguns casos, discursivamente apresentado pela ideia da distinção e honra em dar continuidade ao nome familiar na empresa. Em outros casos, o ingresso no mundo do trabalho aparecia como contingenciado pelas necessidades econômicas da família, evocando o lamento pelo estudo interrompido ainda na infância. É importante observar também que a transmissão aos filhos do cargo ocupado pelos pais era igualmente garantia de continuar morando na casa cedida pela fábrica (Lopes, 2011), o que aparecia então como uma economia doméstica importante.

Ao mesmo tempo, aprender um ofício era possibilitado por uma rede de cooperação estabelecida no interior de cada seção, sendo fundamental a figura dos funcionários antigos no serviço que cumpriam um papel de instrutores. Da relação com os instrutores dependia uma série de conhecimentos e vantagens secundárias, pois além de conhecer o processo de produção, através da experiência transmitida, o novato entenderia melhor o funcionamento das redes estabelecidas dentro da seção, assim como as práticas solidárias e as formas 
de cooperação que amenizavam as condições difíceis com que se desenvolvia o dia a dia no trabalho.

A categoria trabalho aparece como fundamental nas narrativas, numa amplitude a partir da qual é possível compreender todos os âmbitos da vida nos quais a experiência da fábrica aparece circunscrita. A condição de trabalhador é uma lente pela qual se pode observar a história de toda uma vida, da infância até a senilidade, num percurso não linear e nem sempre bem delimitado. Em algumas entrevistas, ingressar na fábrica como funcionário assumia a ideia de liberdade, pois possibilitava ao sujeito o convívio com pessoas externas ao ciclo familiar e a participação em uma sociabilidade instaurada dentro dos grupos formados nas seções de trabalho.

Essa liberdade, no entanto, era condicionada e vigiada, sobretudo para aqueles que tinham familiares trabalhando na fábrica, pois todos os comportamentos considerados desviantes pela empresa eram transmitidos aos familiares, sendo igualmente possível que as sanções fossem a eles imputadas.

No contato com essa comunidade de informantes foi possível observar que a maior parte das narrativas convergia para uma relativização dos esforços físicos, ainda que deles decorressem patologias ou deformações permanentes. O reconhecimento dessas marcas no próprio corpo remete às condições nas quais o trabalho era executado, sendo que a introdução sistemática de normas de segurança só ocorreu a partir de 1956, num processo de modernização da produção que culminou com a contratação de uma empresa americana Wernertex, a qual permaneceu na Rheingantz de 1956 a 1958. Pressionado pela necessidade de acompanhar o que já ocorria em outras empresas têxteis do Rio Grande do Sul, no que se refere à modernização do maquinário e à introdução de novos métodos de trabalho para lidar com as fibras sintéticas, o então diretor da empresa, João de Miranda Rheingantz, autorizou o contrato dessa empresa de engenharia industrial.

O trabalho desenvolvido pela Wernertex foi marcado por conflitos e discordâncias que se tornaram problemas graves na gestão da empresa. $\mathrm{O}$ grupo de técnicos americanos foi instalado em um escritório adaptado para recebê-los no centro da fábrica, em local que passou a ser conhecido como "a gaiola de ouro”. Desse lugar, as representações que são feitas pelos entrevistados evocam isolamento, um enclave do moderno num conjunto já bastante antigo.

$\mathrm{Na}$ "gaiola de ouro", os técnicos americanos, aplicando a engenharia industrial, faziam incidir modificações na organização espacial da fábrica e 
na relação empregado/máquina no que se refere ao número e desempenho de produção. O remanejamento e consequente diminuição de pessoal ativo, as mudanças nas relações de trabalho e as alterações na estrutura do prédio fabril foram os elementos que as memórias desse período mais evocaram, como forma de uma desordem trazida de fora para dentro, num estranhamento constante entre os trabalhadores, os mestres de origem alemã e os técnicos americanos. Nas falas dos antigos trabalhadores, esse período foi marcado pelo afloramento de conflitos de ordem hierárquica, uma vez que o comando da empresa passou a ser regido por sujeitos externos a ela, o que foi agravado pelo fato de que para os mestres era uma afronta terem que se submeter a um saber de cuja constituição estavam excluídos, devido à falta de formação técnica específica.

\section{As máquinas: memória de gestos, saberes e técnicas}

A relação estabelecida com as máquinas e o valor simbólico conferido a elas, como elementos de identidade, é um dos eixos sobre os quais se articularam as narrativas. A prática cotidiana do trabalho, associada à curiosidade e à observação, conferia um conhecimento que era manejado e utilizado como forma de distinção dentro da fábrica. Entender o funcionamento da máquina era fundamental para solucionar problemas cotidianos e demonstrar autonomia frente aos conhecimentos de técnicos especializados. É essa aptidão para conhecer materiais e dominar as formas como as máquinas operavam que, na memória, atuava como o diferencial entre o operário do passado e aquele do presente.

O saber-fazer é, no que tange às atividades que não passam por uma formação profissional estritamente técnica, a capacidade de compreender seu ofício como uma extensão da experiência, o que confere à capacidade de prever problemas e antecipar soluções sem que esse conhecimento passe, necessariamente, pelo aprendizado formal. Jean-Louis Tornatore (1991), em seu estudo sobre os operários da construção naval em Marselha, aponta para a competência profissional construída por meio da experiência, o que o autor denomina de vice, demarcando a diferença entre um operário passivo e aquele que consegue se desvencilhar dos problemas, encontrar soluções e formas

de resolução dos mesmos. É, portanto, o desenvolvimento de um esquema cognitivo especializado, de tarefas aplicadas de maneira sistemática, mas não

Horizontes Antropológicos, Porto Alegre, ano 19, n. 39, p. 69-98, jan./jun. 2013 
exatamente definidas pela linguagem, que confere a habilidade de fazer bem, dito de outra forma, o saber-fazer (Descola, 2006).

Se a aquisição de um saber-fazer não dependia unicamente do aprendizado técnico, é preciso que isso seja atribuído a certos elementos que atuavam em conjunto. Na fábrica têxtil esse saber-fazer construía-se pelo domínio do conhecimento sobre as máquinas, seus processos de funcionamento e materiais utilizados, como a lã e o fio obtido pelo estiramento da mesma. Em todos os setores da Rheingantz, da lavagem e banho químico até a tecelagem e tapeçaria, o fundamental, de acordo com os informantes, era reconhecer se o fio era resistente ou não, do que dependeria um maior ou menor volume de produção ao final do período. Esse conhecimento advinha do toque para que fosse possível saber a densidade, identificando a composição do fio pela viscosidade, odor e coloração. Tal como afirma Sueli, uma antiga fiandeira: "teve um contramestre, seu Jaime, ele pegava as maçarocas [cilindro em torno do qual era enrolado o fio] que estavam caídas no chão e dizia: esse é tal fio, tal partida, tal cor... ele sabia, e hoje a maior parte não conhece nada” (Botelho, 1981).

A descrição do processo de transmissão desse saber-fazer não possibilita compreender como efetivamente isso ocorria (Rasse, 1991). O caráter quase sempre minimalista dessa descrição aponta para um conhecimento intuitivo confirmado pela repetição. Entretanto, deter esse conhecimento poderia ser a forma de impor-se numa estrutura hierárquica fundada sobre a competência técnica formal.

O declínio da empresa é representado pela desagregação desse universo constituído pelo tênue equilíbrio entre os dois campos de conhecimento: o técnico e o empírico, desencadeado pela missão modernizadora imposta pelos técnicos americanos. A introdução de novos métodos, equipamentos e formas de racionalização da produção era recuperada como a desestabilização de um sistema que permitia a sincronização de práticas técnicas e práticas sociais.

A ruptura com esse sistema anterior, o das “velhas paredes”, era apontada pelos relatos memoriais como um dos grandes fatores que levaram à falência da empresa, sobrepondo-se a outros, como a incapacidade de acompanhar as novas tecnologias aplicadas ao setor têxtil e o mau gerenciamento interno da fábrica.

Horizontes Antropológicos, Porto Alegre, ano 19, n. 39, p. 69-98, jan./jun. 2013 


\section{0 tempo do luto}

É possível afirmar que há um consenso memorial sobre esse período anterior, no qual as representações sobre a fábrica giram em torno da "grande família”, dos chefes como rigorosos e justos, dos conflitos como apaziguados ou inexistentes e de acordos possíveis numa ordem que vai perdendo a rigidez frente à necessidade de aumento da produção. A fábrica torna-se o centro de uma vida desejável, e dessa narrativa constrói-se o mito da Idade de Ouro, uma remodelação do passado cuja finalidade é possibilitar a continuidade da existência no presente. No plano discursivo vê-se que o momento que se aproxima da ruptura (o fechamento da empresa) é abordado de maneira fragmentada, instável e controversa (Goux, 2002, p. 102). Tudo parece se desordenar quando entra no período que antecedeu ao fechamento, período no qual a desestabilização, a insegurança e o sofrimento impõem-se como sentimentos e representações possíveis.

Nas fichas de registro do departamento pessoal há um considerável aumento de licenças e punições por infrações cometidas pelos operários no período que vai de 1955 até 1968. Essas infrações repetem-se em várias fichas sob o título de atos de sabotagem, dentre os quais os mais recorrentes são: ter "calçado maldosamente” os limpadores de fios da máquina; deixar enrolar a lã até quebrar a máquina; fazer torção contrária no fio; estragar tapetes; rasgar o couro da máquina; rasgar a andadeira da máquina; desperdiçar tapume; quebrar lançadeiras; colocar ferro sob a roda do caminhão. Tais atitudes ficavam atestadas pelos documentos e demonstravam um descontentamento crescente dos trabalhadores frente ao atraso de salários e à "política de degola”, como era apresentado o sistema de redução de pessoal, e à suspensão de algumas vantagens como as horas extras, frutos da reforma administrativa proposta pela equipe da Wernertex.

Dentre essas práticas de sabotagem, as mais impactantes foram as empreendidas pelos antigos mestres, contrariados pelo sombreamento causado pelos técnicos americanos. A estratégia usada pelos mestres foi a de omitir conhecimentos e pedir a aposentadoria, nos casos em que era possível. "Os velhos alemães foram se aposentando e levaram as fórmulas boas, só deixaram as ruins... então se fazia os cobertores, mas vinha tudo de volta com reclamações” (Botelho, 1981), ou ainda “o alemão dos tapetes não quis deixar 
a receita dos tapetes para ninguém, ele sempre dizia que não ia deixar, deixou algumas coisas que dava para se orientar somente, uns desenhos, mas a receita mesmo, isso ele levou com ele” (Honorina Britto, entrevista em 24/09/1998).

O ano de 1969 foi marcado por um desmonte gradativo da estrutura produtiva da empresa, o que repercutiu nos demais setores, como o social e o assistencial, os quais recebiam diretamente as influências das oscilações econômicas pelas quais passava a fábrica. Em 1961, é feita a transferência, mediante venda do controle acionário, para um grupo paulista, Irmãos Abdalla, que era, na verdade, um conglomerado de empresas de diferentes ramos. O interesse na aquisição de uma empresa do porte da Rheingantz, com problemas de funcionamento, gerou suspeita entre os trabalhadores sobre as reais intenções desses empresários e deu-se início a um movimento de resistência, constituído de atos de sabotagem contra o que os informantes definem como uma "sangria” na Rheingantz: o envio para São Paulo dos produtos contidos no estoque.

Os problemas na administração da empresa começaram a se avolumar. O pagamento dos salários foi mantido com regularidade apenas nos quatro primeiros anos, porém as dívidas contraídas com os fornecedores dos insumos básicos ao funcionamento da produção foram sendo postergadas, bem como as obrigações previdenciárias. O fechamento da creche em 1962 e a desativação da Sociedade de Mutualidade em 1967 foram os dois maiores golpes na comunidade fabril, de acordo com os informantes.

Os anos que seguem são marcados por confrontos dentro do grupo de acionistas e por acusações de má versação do orçamento da fábrica por parte da administração central.

Em 1963, apesar do desencanto e da falta de perspectiva no futuro, a Rheingantz comemorava 90 anos. Um almoço coletivo no pátio da fábrica e uma pequena solenidade religiosa pareciam marcar simbolicamente o final de uma era, e os relatos avançavam para cenas de sofrimento e revolta, assim como de fé e crenças, como é o caso da construção do altar que abriga até hoje a estátua de Nossa Senhora de Fátima no pátio central.

As atitudes da administração eram interpretadas como um descompromisso absoluto com os funcionários e, embora as reclamações trabalhistas começassem a se avolumar, a empresa não cumpria as sentenças ditadas pela justiça. O Sindicato dos Trabalhadores em Fiação e Tecelagem, cuja diretoria à época era composta por operários da Rheingantz, mobilizou-se por tornar

Horizontes Antropológicos, Porto Alegre, ano 19, n. 39, p. 69-98, jan./jun. 2013 
pública a situação da fábrica e levou à justiça uma série de reclamatórias trabalhistas. Esse movimento reivindicatório foi interpelado pela instauração do regime militar, a partir de 1964, tendo sido a direção do sindicato destituída e nomeado um interventor, Helio Lewis da Silveira, que narra o momento em que foi abordado pela polícia militar:

Acho que eles fizeram uma pesquisa na vida de todas as pessoas que trabalhavam aqui... porque quando encostou aqui a caminhonete da Marinha e nos procurou um sargento, pedindo que fôssemos com ele até a Capitania dos Portos, eu pensei que ia ser preso, porque levavam muita gente lá para o navio Canopus, que ficava lá na Barra. Eu perguntei aos outros dois companheiros se eles tinham alguma implicação política e eles também não tinham, e aí quando chegamos lá na Capitania, o Capitão dos Portos nos pediu para colaborar com eles, eu procurei sair fora, mas já não dava mais. (Helio Lewis da Silveira, entrevista em 06/02/1999).

Foram intensificadas as ações de sabotagem contra os caminhões que levavam o estoque para São Paulo, porém com uma motivação política, almejando enfraquecer o diretor do Grupo Abdalla, opositor ao regime.

A partir de ações comprometidas com o abrandamento e o afastamento de lideranças com posições de esquerda, o sindicato foi perdendo a credibilidade e a força de representação dentro do movimento dos trabalhadores da Rheingantz. Em janeiro de 1968, a fábrica amanheceu ocupada por contingentes da Brigada Militar, sob ordens do Departamento Federal de Segurança Pública, cujo objetivo era o de impedir atos de protesto no interior da mesma, e ali permaneceram por uma semana (Jornal Rio Grande, 1968).

Com salários atrasados e perda de muitos direitos, alguns operários deixaram a empresa e foram buscar outras alternativas de emprego. Outros, entretanto, permaneciam na esperança de que a fábrica voltasse a se recuperar, o que se tornava cada dia mais distante, pois, impossibilitada de produzir em razão da escassez de matéria-prima e com dívidas trabalhistas gigantescas, o colapso da Rheingantz tornou-se irreversível. Em 15 de março de 1968 foi, então, decretada a falência da fábrica que, pela primeira vez em 90 anos, fechava as portas.

As representações de morte aparecem nas falas referentes a essa fase em que, pouco antes de decretada a falência oficial da firma, os funcionários foram alertados pelo sindicato de que deveriam continuar indo na empresa, 
pois em caso contrário poderia ser configurado abandono de emprego, o que resultaria na perda dos direitos legais a indenizações pleiteadas contra a fábrica. Assim, por seis longos meses, aqueles que ainda suportavam cumpriam parcialmente o horário de trabalho, sentados nas seções, sem trabalhar porque não havia matéria-prima e também em razão do processo embargatório infringido contra a fábrica, que colocou o maquinário sob custódia da justiça. Da morte simbólica, decorrente do estancamento do barulho dos teares e dos filatórios, a morte física veio ocupar um espaço no interior da comunidade, como afirma seu Hilso, dizendo que no ano em que fechou a Rheingantz foram registradas 16 mortes de funcionários da empresa, seja por suicídio ou "paixão”, tal como afirma o informante.

O desaparecimento de um mundo do trabalho idealizado e representado através de categorias, como família, dignidade e juventude, deixou sentimentos de indignação e revolta, substituídos no presente por decepção e silêncio. Falar desse período terminal da fábrica foi motivo de evitação e tristeza, uma memória impedida, indisponível e, pela força da melancolia, difícil de esquecer (Ricoeur, 2007, p. 423).

Esse esquecimento estratégico e voluntário permitiu, paradoxalmente, a constituição de uma nova identidade e de um novo tempo para a Fábrica Rheingantz, o tempo da patrimonialização ou, usando a expressão de Gaetano Ciarcia (2006), a "perda durável”, no sentido da construção de uma nova temporalidade, não mais somente a da memória e suas evocações, não apenas o presente com suas contradições, mas a do passado expandido e ressignificado em risco de desaparecimento.

\section{0 tempo do patrimônio}

Os esforços por manter a fábrica aberta, simulando existir alguma atividade produtiva em seu interior, mantiveram-se até o falecimento de seu Hilso, o "guardião da Rheingantz". Sem alguém que se dispusesse a cumprir esse papel e com o avanço da idade dos antigos trabalhadores, a antiga fábrica fechou-se definitivamente ao mundo exterior em 2001. A partir desse momento acelerou-se o processo de degradação com registro de casos de vandalismos e roubos de materiais, como tubulações em bronze.

A audiência pública de julho de 2009 foi um marco no processo de conversão da memória sobre a fábrica em um processo de conscientização

Horizontes Antropológicos, Porto Alegre, ano 19, n. 39, p. 69-98, jan./jun. 2013 
patrimonial sobre ela. Recuperar e impedir o desaparecimento dos traços desse passado foi a ênfase desse ato que reuniu atores sociais, tais como vereadores municipais, Judiciário e Ministério Público federais, universidades, ex-funcionários da Rheingantz. Atitudes emocionadas surgiram de vários membros do poder público e da plateia, como o relator da audiência que se remeteu à sua infância e à necessária recuperação do passado numa cidade que agora olha para seu futuro (Rio Grande, 2009).

Sem desconsiderar que anterior a esse ato público já tivessem acontecido outros de igual natureza, bem como manifestações dessa comunidade de ex-trabalhadores em prol da patrimonialização do complexo fabril, passa-se a observar as repercussões desse evento nas mídias e nos discursos locais, que com mais ênfase apontavam para a fábrica como patrimônio da cidade, tudo como se de fato a emoção patrimonial tivesse sido ativada pelos discursos e ações do poder público, tal como a aplicação do princípio da adjudicação (entrega do bem pelo devedor) ao antigo prédio que abrigou o Cassino dos Mestres e Sociedade de Mutualidade, repassado à administração municipal para que fosse efetivado seu restauro (Rio Grande, 2009). Outras reações, algumas de caráter contrário ao tombamento das casas da Vila Operária, ${ }^{10}$ foram observadas num movimento que evidencia essa ativação patrimonial mobilizada no interior da comunidade. O sentido de ativação patrimonial elaborado por Llorenç Prats (1998), referindo-se à ideia de que elementos que integram os repertórios culturais, para que adquiram autoridade e representatividade, devem ser previamente legitimados como construção social, adquire nesse caso um sentido bastante profundo. Segundo Prats (2005, p. 20), a ativação, mais do que a valorização, tem a ver com o discurso "mais ou menos explícito, mais ou menos consciente, mais ou menos polissêmico, mas absolutamente real” baseado na seleção de elementos integrantes da ativação, na ordenação e na interpretação dos mesmos, construindo assim um "caráter sagrado e imutável” (Hernández Ramírez, 2007, p. 7) de objetos a serem elevados à categoria de símbolo coletivo, podendo, portanto, representar um vestígio de passado que une os sujeitos no presente.

\footnotetext{
${ }^{10}$ No dia 20 de dezembro de 2010 foi consumido pelo fogo o sobrado de traços enxaimel onde havia sido a residência dos mestres. A tese de incêndio criminoso, buscando resguardar o valor do terreno, começa a ganhar espaço dentro da cidade sem que, no entanto, tenha sido comprovada.
} 
O tempo da memória, que para fins dessa pesquisa foi considerado como esse anterior à criação dos discursos e de dispositivos patrimoniais, fazia-se observar na relação dos sujeitos com os evocadores da recordação, justificando assim os acervos pessoais formados por objetos industriais, fotografias, periódicos publicados pela empresa, documentos de trabalho, cadernos de anotações, etc. Nesse tempo da recordação, os sentidos são individualmente construídos e participam dessa modulação do tempo da vida, pautados pelo trabalho: reconstrói-se a própria trajetória a partir de uma ordenação demarcada pelo tempo do trabalho "no tempo da Rheingantz" (Eckert, 2012). Nesse sentido a memória como representação presente de uma coisa ausente (Ricoeur, 2007) remete à ideia de traços e vestígios presentes na duração.

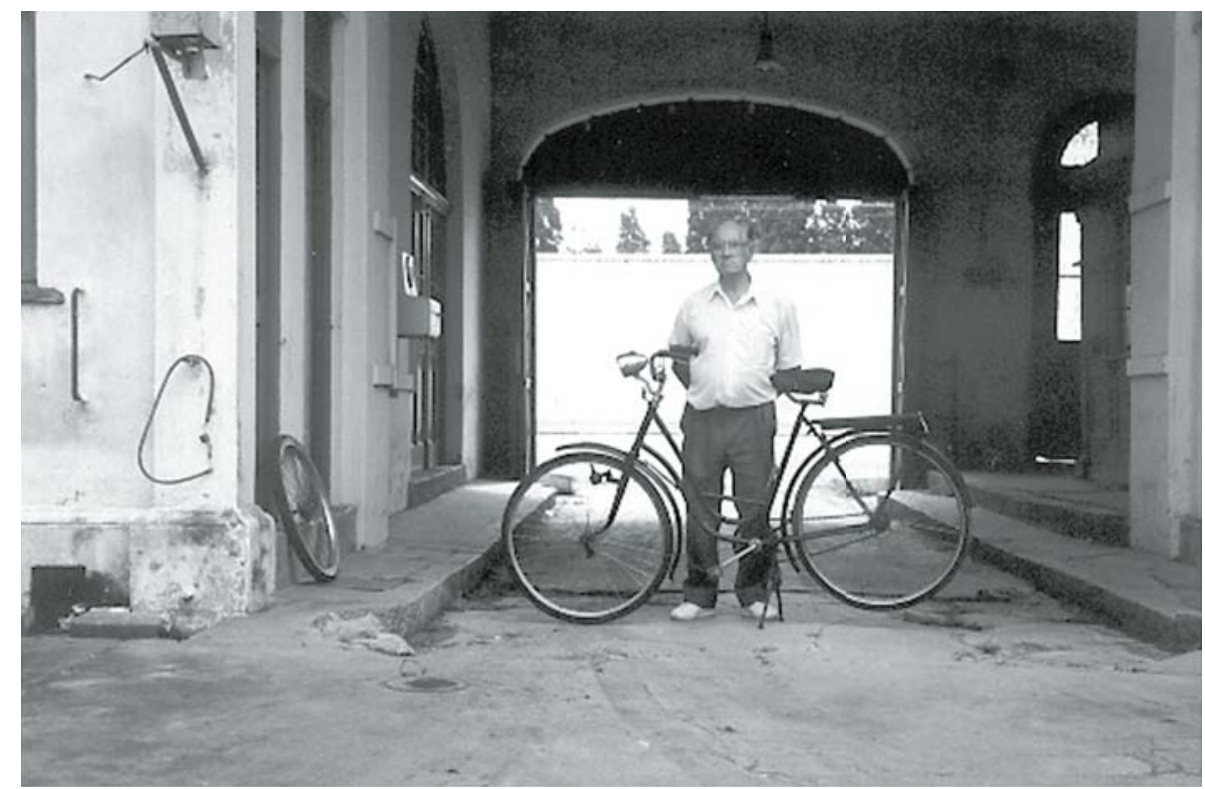

Figura 4. Seu Hilso e a bicicleta alemã (acervo pessoal).

A dimensão espacial adquire então um sentido mais profundo, pois tenderia a assegurar o sentimento de continuidade dos grupos de acordo com Maurice Halbwachs (1990, p. 20). Os traços inscritos no espaço são 
constantemente reapropriados e funcionam como marcas implicadas no processo de apropriação simbólica do mesmo (Veschambre, 2008, p. 14). A transposição desse espaço-memória para espaço-patrimonial resulta da consciência de um sentimento de pertencimento e, ao mesmo tempo, o reconhecimento desse conjunto como patrimônio reafirma e sela em definitivo o processo de desindustrialização (Di Méo, 2007).

O processo de patrimonialização da Rheingantz vem sendo marcado por ações externas - poder público e experts - que por vezes desconsideram os lugares nos quais a sedimentação do passado parece ser mais evidente aos atores locais. O descompasso entre as decisões sobre os objetos patrimonializáveis eleitos e mediados pelo poder público e os atores locais (a escolha do Cassino dos Mestres como prédio a ser restaurado em detrimento de outros igualmente importantes e que apareciam em maior destaque nas entrevistas, como o do Grupo Escolar Comendador Rheingantz, pensado por alguns moradores para sediar um museu da Rheingantz e atualmente destinado a ser um restaurante) são reveladores da dificuldade de fazer operar a noção de transmissão, o que, de acordo com Dominique Poulot (1998, p. 10), é condição essencial para que se estabeleça o futuro do passado. Há que se considerar, no entanto, a ideia de que o patrimônio é construído sobre a perda, o desaparecimento, e, especificamente nesse caso, a desagregação de uma atividade industrial e sua transformação em lugar para a memória da atividade industrial. Nesse sentido, o patrimônio é sempre associado a algo que se perdeu, uma ruptura entre o que foi e o que se reinventa, o intransmissível, portanto.

Espaço entre dois mundos, o do trabalho e o do patrimônio, esse conjunto fabril possibilita que se interrogue sobre as mutações sofridas pelo espaço urbano e as transformações que ocorreram na cidade, que se abre, simbolicamente, pelo signo visual da indústria têxtil. ${ }^{11}$

A vontade política de preservar os restos, expressa pelo tombamento do conjunto fabril, levada a termo pelo Iphae, não poderá prescindir de compreender que nesse lugar subsiste, pela força de uma representação compartilhada de passado, uma identidade que a ele se vincula e uma paisagem composta pela materialidade e imaterialidade da memória.

11 O pórtico de entrada na cidade de Rio Grande, pela chamada Avenida Presidente Vargas, é a estilização de uma máquina de costura em alusão às fábricas têxteis da cidade na década de 1950, quando foi erigido.

Horizontes Antropológicos, Porto Alegre, ano 19, n. 39, p. 69-98, jan./jun. 2013 


\section{Referências}

BOTELHO, S. Depoimento concedido em 23 nov. 1981. Acervo Fábrica Rheingantz, Centro de Documentação Histórica Professor Hugo Alberto Pereira Neves, Fundação Universidade do Rio Grande, Rio Grande.

CIARCIA, G. La perte durable: étude sur la notion de "patrimoine immatériel”. Charenton-Le-Pont: Lahic, 2006. (Carnet du Lahic, n. 1). Disponível em: <http://www.iiac.cnrs.fr/lahic/sites/lahic/IMG/pdf/Ciarcia_perte_durable. pdf $>$. Acesso em: 20 out. 2009.

DIARIO DE RIO GRANDE. Rio Grande, p. 2, 19 abr. 1887.

DESCOLA, P. Introduction. In: D’ONOFRIO, S.; JOULIAN, F. (Org.). Dire le savoir-faire, gestes, techniques et objets. Paris: l'Herne, 2006.

DI MÉO, G. Identités et territoires: des rapports accentués en milieu urbain?, Métropoles, n. 1, 15 mai 2007. Dispónível em: <http://metropoles.revues.org/ document80.html>. Acesso em: 29 maio 2009.

ECKERT, C. Memória e trabalho: etnografia da duração de uma comunidade de mineiros do carvão (La Grand-Combe,França). Curitiba: Appris, 2012.

FERREIRA, M. L. M. Os três apitos: memória coletiva e memória pública, Fábrica Rheingantz, Rio Grande, RS, 1950-1970. Tese (Doutorado em História)-Faculdade de Filosofia e Ciências Humanas, Pontifícia Universidade Católica do Rio Grande do Sul, Porto Alegre, 2002.

GOUX, J.-P. À propos de mémoires de l'enclave. Cahiers CDHT,CNAMEHESS, n. 11, p. 93-104, 2002.

HALBWACHS, M. A memória coletiva. São Paulo: Vértice, 1990.

HALBWACHS, M. Les cadres sociaux de la mémoire. Paris: Albin Michel, 1994.

HARDMAN, F. F.; LEONARDI, V. História da indústria e do trabalho no Brasil: das origens aos anos vinte. São Paulo: Global Editora, 1982. 
HERNÁNDEZ RAMÍREZ, J. El patrimonio activado. Patrimonialización y movimentos sociales en Andalucía y la ciudad de México. Dimensión Antropológica, año 14, v. 41, p. 7-43, 2007.

JORNAL RIO GRANDE. Rio Grande, p. 3, 5 jan. 1968.

LASMÈNES, M.-A. Souffleurs de verre, mémoires intimes au travail. Conserveries mémorielles, n. 11, 2011. Disponível em: <http://cm.revues. org/958>. Acesso em: 7 jul. 2012.

LOPES, J. S. L. Memória e transformação social: trabalhadores de cidades industriais. Mana, v. 3, n. 17, p. 583-606, 2011.

LUCA, R. Le temps du travail. Conserveries mémorielles, n. 11, 2011. Disponível em: <http://cm.revues.org/966>. Acesso em: 4 maio 2012.

MATHIEU, R.; GORGEU, A. Mémoire et conditions de travail: analyse d'entretiens auprès d'ouvriers. Conserveries mémorielles, n. 11, 2011. Disponível em: <http://cm.revues.org/975>. Acesso em: 2 ago. 2012.

NORA, P. Entre mémoire et histoire, la problématique des lieux. In: NORA, P. (Dir.). Les lieux de mémoire. Partis: Gallimard, 1984. p. XVII-XLII.

POULOT, D. Les patrimoines et les aventures de la modernité. In: POULOT, D. Patrimoine et modernité. Paris: L’Harmattan, 1998. p. 7-67.

PRATS, L. El concepto de patrimonio cultural. Política y Sociedad, n. 27, p. 63-76, 1998.

PRATS, L. Concepto y gestión del patrimonio local. Cuadernos de Antropologia Social, n. 21, p. 17-35, 2005.

RASSE, P. La cité aromatique. Terrain, n. 16, 1991. Disponível em: <http:// terrain. revue.org/index2993.html>. Acesso em: 14 out. 2010.

RICOEUR, P. A memória, a história, o esquecimento. Campinas: Unicamp, 2007. 
RIO GRANDE. Câmara de Vereadores. Ata $n^{\circ} .10$ de 9 de julho de 2009: Audiência Pública Vila Operária Rheingantz. Rio Grande, 2009.

RIO GRANDE DO SUL. Secretaria da Cultura. Portaria SEDAC n. 38/2012: tombamento Complexo Rheingantz. Diário Oficial, Porto Alegre, p. 63, 16 jul. 2012. Disponível em: <http://www.iphae.rs.gov.br/modGerArquivos/ ModGerArquivosDownloadOpen.php?OID=43408\&NOME=Portar ia_38_2012.pdf>. Acesso em: 30 ago. 2012.

TORNATORE, J.-L. Être ouvrier de la Navale à Marseille. Terrain, n. 16, 1991. Disponível em: <http://terrain. revues.org/index3000.html>. Acesso em: 21 nov. 2010.

VESCHAMBRE, V. Traces et mémoires urbaines, enjeux sociaux de la patrimonialisation et de la démolition. Rennes: Presses Universitaires de Rennes, 2008. 